\title{
Music and Music Ethnography as Reflexivity Tools in Adult Learning
}

\author{
Dr. Irene Theodosopoulou, Musicologist, Ph. D
}

\author{
Faculty Member, Hellenic Open University, Studies in Greek Civilization, ELP40: Arts II: Overview of Greek Music and \\ Dance (2006-2016), Faculty Member, Schools of Second Chance (Acharnon School, 2012-2013)' \\ eirinitheodosopoulou@hotmail.com
}

\section{Doi:10.5901/mjss.2016.v7n3s1p247}

\begin{abstract}
Music and music ethnography can evoke reflexivity in adult learning. The aim of the text is to highlight -out of two "ethnographic" cases- the ability of using music and ethnographic research as tools of transformative learning in adult education through recollective experiences. Reflexivity, as an analytical and interpretive tool in music ethnography, is used in the design of a research, in the discussion between ethnographers/musicologists and musicians or non musicians -carriers of a "tradition"- or in the composition of an ethnographic "text". In reality, discussing with the different "other" is posing questions to oneself. Listening to a melody as adults, we associatively re-create memories and older experiences. The research was based on the use of music and musical ethnography as tools of transformative learning in two cases: firstly, in culturalists of the tertiary education of the Hellenic Open University and secondly, in adult students of the secondary education who were carrying out researches in the frame of a project entitled "Narrations about music and dance: Narrations about life". The research took place in the years 2012-2013 and was based on qualitative methods of analysis (interviews and participatory observation were used). Visual arts are already used as analytical tools in adult learning. This article underlines the necessity of initiating a fertile discussion on the embodiment of music and ethnographic research, as useful reflexivity tools, in adult learning.
\end{abstract}

Keywords: Reflexivity, ethnographic research, music, transformative learning, adult learning

\section{Introduction}

In music ethnography, ethno-musicologists and anthropologists often use "reflexivity" in a research (Nettl, 2002). Reflexivity (Kavouras, 1994; Kavouras, 2002; Geertz, 1973; Gefou - Madianou, 1998; Gefou - Madianou, 1999) as an analytical and interpretive tool is used both during a field-research aiming at the study of e.g. the musical tradition of a geo-cultural area (Chtouris, 1999) and during the interpretation of the research data. However, it is mainly used during the composition of an "ethnographic text". This is where the researcher/ethnographer is called upon to come to an internal "dialogue" with his already existing experiences as adult and use the data of the external "dialogue" with his interlocutors/co-feasters during the research, attempting a parallel "emic" and "etic" analysis (Clifford - Marcus, 1986; Geertz, 1973; Marvin, 1968; Gefou - Madianou, 1999). The viewpoint of an ethnographer is the viewpoint of the "other" but, undoubtedly, it is also the result of the experiences of the ethnographer him/herself, which he/she has acquired during his/her life. This dialogical procedure and polyphony (Bakhtin, 1980) between oneself and the "other" becomes the starting point for the elaboration of self-knowledge and self-definition.

Adult learning and lifelong education (Vergidis \& Kokkos, 2010; Karavakou, 2011) are largely based on the recollection and the use of one's experiences (Karavakou, 2013a; Karavakou, 2013b; Kokkos, 2005; Rogers, 1999). Music can become the starting point for reflexivity in adult learning and can be used by adults in the learning process and search for knowledge, on various levels. The consultant teacher is there to encourage and guide the adults in the learning process and the commencement of any research procedure they attempt.

In the frame of this proposal, there are elements resulting from my serving as trainer for adults on a double level: firstly, the level of the consultant teacher in tertiary education, where the analytical tool of reflexivity is put to multiple reading and interpretation both in an "emic and etic" level of analysis by culturalists and secondly, the level of the consultant teacher in the institution of Schools of Second Chance (Vergidis, 2004), where there are developing matters about the integration of socially vulnerable groups and issues concerning the contribution of projects in learning, which arise through the researches carried out by the trainees themselves around music and dance.

More specifically, what I am discussing is the example resulting from the reference and use of ethnographic studies by culturalists, in the frame of distance learning for adults in tertiary education (Kokkos \& Lionarakis, 1998), where 
the use of such tools as reflexivity is largely used consciously and secondly, the use of self-reference and reflexivity in the project carried out by the School of Second Chance in the area of Acharnes during 2012-2013 entitled "Narrations about music and dance: Narrations about life".

\section{Research Methods}

The research was carried out in the years 2012-2013 and was based on ethnography and its methods (interviews and participatory observation were used).

Ethnography, as a method and process of collecting primary material through 'field research', was used firstly, by the trainees and secondly, by the ethnographer - educator. It is through the dialogue we learn about us. In the frame of an ethnographic research several issues arise related to the following: the method, the research techniques, the fieldresearch practices, the different 'presents' of the research, the ethnographic 'texts' (finals but not definite) on the pursuit of the 'others' experiences'. The research was based on qualitative methods of analysis in order to highlight the different discourses of the trainees about music, culture and self-evaluation of one's experiences. Interviews and participatory observation were used as tools in the above studies. Biographical discourses and ethnographic notes were used serving us with 'vehicles' for the 'performance' of ethnographic experiences. Ethnographic methods related to the music were regarded as a starting point for reflexivity procedures and reconsideration of ways of thinking and acting. The ethnographic essays can be a 'mirror' through which real, fantastic and symbolic identities are reflected (Lekkas, 2003). The continuous pursuit of 'others' experiences' contributes to the comprehension of the ethnographer's own experiences (trainees' experiences as ethnographers and ethnographer's -educator's reflective experiences).

\section{Literature Review}

Transformative learning (Kokkos, 2005; Kokkos \& Alhadeff-Jones, 2011; Kokkos, 2011; Mezirow, 1991; Taylor, 2000) is based on orthological dialogue and meaningful events in the lives of the trainees. It is a field where critical reflection and reconsideration of experiences and ways of thinking are used in order to acquire new knowledge and overcome difficulties, altered attitudes (Kokkos, 2001) and behaviors as well as redefine one's adulthood.

The use of visual arts in transformative learning, in dialogical form, is already a reality (Kokkos, 2011; Kokkos, 2012a; Kokkos, 2012b; Kokkos \& Alhadeff-Jones, 2011). Knowledge, active listening and participatory observation in music ethnography in combination with the creation of an ethnographic "text" can be helpful in transformative learning and its operations.

\section{Aims of the Article}

The questions posed concern the importance of ethnographic research (Barz, 1997; Bohlman, 1991; Cooley, 1997; Clifford \& Marcus, 1986; Nettl, 2002; Gefou - Madianou, 1999) and participatory observation as tools of learning and searching for knowledge through our adult experiences. What is also examined is the role of music as a starting point for reflexivity in adult learning and the extent to which an ethnographic research contributes to our socialization, our selfdetermination and the acceptance of our dissimilarity as well as the transcendence of any potential difficulties which we have to face in a constantly changing socio-economical and cultural environment, through multiple identities (Gefou Madianou, 1998, Lekkas, 2003, Fillipou, F., Goulimaris, D., Serbezis, V., Genti, M. \& Davoras, D. 2010;) that we have to manage on a personal or collective level.

The aim of this article is to initiate a fertile concern and dialogue on the use of ethnographic research and reflexivity through music in adult learning. Two main objectives of the article are: 1. to examine if music (as a meaningful event and as sounds) can be used as an educational tool in transformative adult learning and 2. to examine if music ethnography and participatory observation can be used as tools of searching for knowledge in adult learning on the pursuit of the narration of the life of the 'other', leading thus to the acquisition of new knowledge through even conflicts. Personal experience is essentially constructed by or through narrative, that is, by the stories we tell ourselves or that others tell about us.

\section{Research Data}

The two groups under study, very different between them as concerns targets and structure, shared nevertheless rich life experiences and a need for learning and research. It is important to observe the way in which certain cultural ideals 
including musical and dance components can be absorbed within an educational process adapted to new data (Karavakou, 2008).

In the frame of Distance Learning for adults (Kokkos \& Lionarakis, 1998) and the undergraduate studies of the Hellenic Open University and especially the Thematic Unity Arts II: An Overview of Greek Music and Dance, culturalistsstudents often use examples from the Greek ethnography, in order to understand cultural phenomena and to define themselves dialogically, through a prism of various identities, cultural practices and musical accomplishments. The emerging discussions among the group members could become subjects of scientific announcements in congresses, since these discussions unfold different experiences, viewed from the angle of a culturalist. Frequently, the expectations, motives (Goulimaris, 2015; Voutsina, Goulimaris, 2016) and targets posed by the educational group, especially during the initiatory meeting, are in conflict with the experiences of the trainees, something that leads them to a certain selfrestriction. The fact that they are culturalists is often in contrast with their need to formulate their proper speech and dialogue, based on their experiences as members of a community, although they frequently wonder whether these experiences can constitute a trustworthy source of knowledge. This is where ethnographic research can be helpful. Ethnographic reflexivity, creation of ethnographic "notes", introduction to the process of research, feedback of the group with new knowledge coming from all members during the group advisory meetings and composition of ethnographic "texts" based on papers indicative for theoretic concern are indispensable stages for the analysis and synthesis of new multiple identities and new experiential situations of reflexivity and absorption of the experiences of the "other" (Babetsos \& Goulimaris, 2014). Thus, starting from ethnographic speech and reflexivity about music and dance and through active listening of various musical examples or videos related to dance within an undergraduate educational frame (Goulimaris, Mavridis, Genti \& Rokka, 2014; Goulimaris, Filippou \& Koupani, 2016; Goulimaris, Koutsouba, Giosos, 2008), the group (both trainees and trainer) changes attitudes and convictions and acquires new knowledge through critical reflection and narration of the experiences of the "other". The recollection of experiences and their classification under a new prism and perspective helps to avoid potential older stereotype relations and tendencies, to accept potential older traumatic experiences and to use this knowledge in the search for Truth.

In the frame of my serving as Music and Art trainer in the School of Second Chance in the area of Acharnes during 2012-2013, I undertook a project entitled "Narrations about music and dance: Narrations about life". The twelve-member group of trainees had a quite different profile. However, the utilization of one's experiences (Karavakou, 2013b) and differences is what impels someone to acquire new knowledge. The educational targets were clear since the beginning of the meetings. According to the needs of the six-month project, each trainee undertook a topic of ethnographic nature in relation to music or dance. For example, one of the trainees was assigned to interview the responsible "pressman" of the master prints in the record factory of "Columbia" and to present the relative ethnographic material. Other trainees were assigned to conduct a field-research in night clubs, interviewing famous instrument players or clients. Finally, some trainees dealt with conducting a bibliography-discography research aiming at presenting the tradition of a certain geocultural area or a linguistic-religious-ethnic group (Empirikos, Moraitis, Lekkas, 2003; Papakostas, Goulimaris, Douma, inpress). The presentation of the results was enacted both within the group and officially, in the school yard of the School of Second Chance of Acharnes, on the last day of the school year in the presence of guests from various institutions of the local society of the area of Menidi.

One of the stages of the composition of a trainee group is the stage of conflict. A second year trainee of the school, about 60 years old, with high scores in all subjects and a proud member of the Greek minority of Arvanites, attempted, after intense discussions with her co-trainees towards the end of the project, to identify many famous representatives of the political, religious and economical life of the country as being Arvanites themselves and to acknowledge them as such, during the official presentation of the results of the research. There was a conflict in the group, since the rest of the members refused to accept her assertions as being unfounded and claiming that, after all, there is no difference whether one is Pontian, Arvanite, Cretan, Epirotan or Sarakatsan. Nevertheless, the trainee insisted on presenting all the above people as Arvanites. Obviously, the identification symbols were particularly strong in her, because they were symbols of "power" and the acceptance of her identity as an Arvanite woman was fortified through the acceptance of the "other" powerful members of society as being Arvanites, too.

\section{Results}

In both cases, where music and ethnographic reflexivity are put in the service of transformative learning, we could talk about the following stages:

Specific stimulus, self-reference, recollection of older experiences, introduction of a new element of subjectivity, doubt, critical reflection, narration of the "other", speech and "dialogue" (internal and external or vice versa), 
reassessment and self-evaluation of experiences, acceptance of the different way of thinking and acting, re-negotiation of identities, self-knowledge, production of new knowledge.

Therefore, we are discussing about the importance of a) "ethnographic research" and our self-definition through hetero-definition, b) participatory observation and self-knowledge by observing the "other" - the importance of a traumatic experience $\mathrm{c}$ ) determination of the stages of reflexivity in adult learning d) experience in order to acquire new knowledge through music and the narration of life stories e) music, in the sense of cultural practices and as a cultural product in the procedures of reflexivity. The questions posed here concern the importance of ethnographic research and participatory observation as tools of learning and searching for knowledge through our adult experiences, the importance of reinforcing recollection tools such as music. In order to prevent trainees from degrading the value and importance of using personal experiences in the process of learning, the role of music is regarded as a starting point for reflexivity in adult learning, while another subject of investigation is the extent to which the processes pertaining to ethnographic research, even through conflicts, contribute to our socialization as adults, our self-definition and the acceptance of our difference as well as the transcendence of potential difficulties we may have to face in a constantly changing socio-economical and cultural environment.

In transformative adult learning, music can be used either in the form of sounds, in order to initiate an internal or external dialogue on the various parameters of music in a specific society, or as a starting point and subject of ethnographic research by adult trainees, in order that they realize their potentials as researchers, delve into identity issues and overcome stereotypical behaviors and attitudes. Regardless of the kind of music that is used, as long as it is part of previous experiences of the trainees, it will contribute to reflexivity and reconsideration of attitudes and behaviors, both theoretically and practically. Whatever ethnographic research concerning music and presumably dance -as long as it constitutes experiential behavior of the biographer- will contribute to the narration of the life of the "other", leading thus to the acquisition of new knowledge. However, the choice of the suitable musical specimens and techniques of ethnographic research is essential, in order to achieve easier and faster reflexivity procedures, depending on the group. The more confrontational the specimens involving personal experiences and standards are, the faster the reflexivity procedures and the reconsideration of ways of thinking and acting become.

\section{Conclusion}

This article highlights the necessity to initiate a theoretical, fertile dialogue between ethnographic researchers and trainers of adults, in order that music and ethnographic research on music can become starting points for reflexivity and analytical tools in adult learning. On a practical level concerning the forthcoming future, trainers of adults may use as tools of transformative learning, not only visual arts but also music, ethnographic dialogue and reflexivity, as well as recollection of experiences connected to cultural "products", identities and life narrations, mainly through confrontational situations and procedures.

\section{References}

Babetsos, E. \& Goulimaris, D. (2014). Personal outcome and leadership as defining factors of satisfaction in the context of the course "Arts II: Overview of Greek Music and Dance" of the Hellenic Open University. Turkish Online Journal of Distance Education, 15, 2, 12-24.


Aesthetics. Translation: G. Spanos. Athens: Plethron].

Barz, Gregory (1997). Confronting the field(note) in and out of the field. Music, voices, texts and experiences in dialogue. In Gregory Barz, Timothy Cooley (Eds.), Shadows in the field. New perspectives for fieldwork in Ethnomusicology (pp. 45-62). New York: Oxford University Press.

Bohlman, Philip (1991). Representation and cultural critique in the history of ethnomusicology. In Bruno Nettl, Philip Bohlman (Eds.), Comparative musicology and Anthropology of music. Essays on the history of Ethnomusicology (pp.131-151). Chicago and London: The University of Chicago Press.

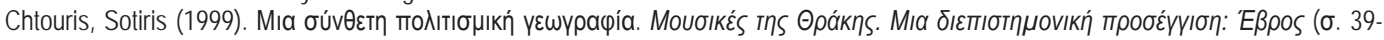

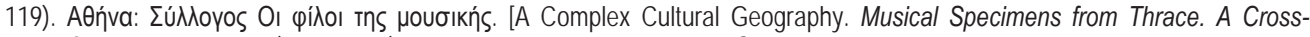
scientific Approach: Evros (pp. 39-119). Athens: Society Friends of Music].

Clifford, James \& Marcus, George (Eds.) (1986). Writing culture: The poetics and politics of Ethnography. Berkley, Los Angeles and London: University of California Press.

Cooley, Timothy (1997). Casting shadows in the field: an introduction. In Gregory Barz, Timothy Cooley (Eds.), Shadows in the field. New perspectives for fieldwork in Ethnomusicology (pp. 3-22). New York: Oxford University Press.

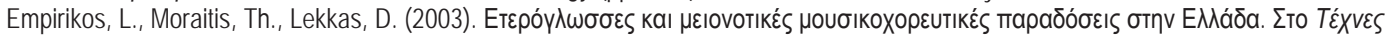




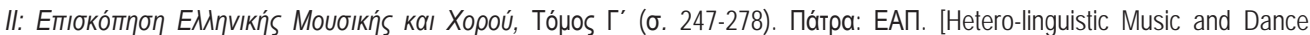
Traditions of Minority in Greece. In Arts II: An Overview of Greek Music and Dance, Volume C (pp. 247-278). Patra: Hellenic Open University].

Fillipou, F., Goulimaris, D., Serbezis, V., Genti, M. \& Davoras, D. (2010) Collective identity and dance in modern urban Greece. Issues in Ethnology and Anthropology, 5, 1, 213-221.

Geertz, Clifford (1973). The Interpretation of Cultures. New York: Basic Books.

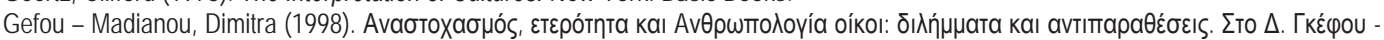

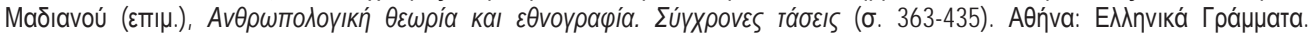
[Reflexivity, Otherness and Anthropology. Dilemmas and Disputes. In Gefou - Madianou (ed), Anthropologic Theory and Ethnography. Modern Tendencies (pp. 363-435). Athens: Ellinika Grammata].

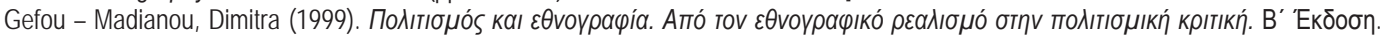

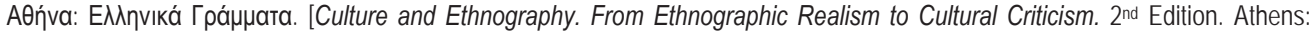
Ellinika Grammata].

Goulimaris, D., Koutsouba, M., \& Giosos, Y. (2008). The organization of a distance postgraduate dance program and the participation of students specializing in dance. Turkish Online Journal of Distance Education, 9,3, 59-73.

Goulimaris, D., Mavridis, G., Genti, M., \& Rokka, S (2014). Relationships between basic psychological needs and psychological wellbeing in recreational dance activities. Journal of Physical Education and Sport, 14, 2, 277-284.

Goulimaris D. (2015). The relation between distance education students' motivation and satisfaction. Turkish Online Journal of Distance Education, 16, 2, 13-27.

Goulimaris, D., Filippou, D.A. \& Koupani, A. (2016). How does the motivational climate differ among adult dancers, within an educational context? Journal of Physical Education and Sport, 16, 1, 252-257.

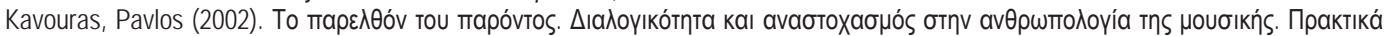

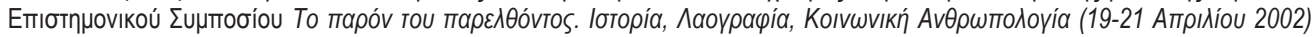

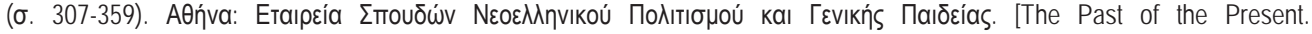
Conversational Ways and Reflexivity in Music Anthropology. Proceedings of the Scientific Symposium The Present of the Past. History, Folklore, Social Anthropology (April 19-21 2002) (pp. 307-359). Athens: Society for the Studies of Greek Culture and General Education].

Karavakou, V., (2008). The importance of cultural and universal ideals in modern education. In K. Boudouris, K.Kalimtzis (Eds.), Paideia: Education in the Global Era. Vol. II (pp.140-154). Athens: Ionia Publications.



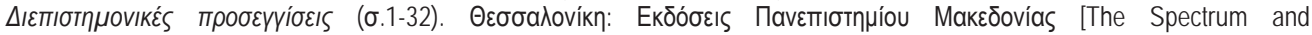
Invitation/Challenge of Lifelong Learning. In Karavakou, B. (ed.), Lifelong Learning: Cross-Scientific Approaches (pp. 1-32). Thessaloniki: Macedonia University Editions].

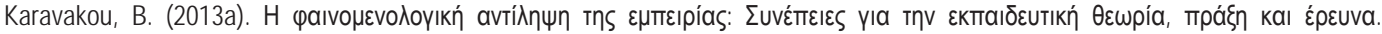

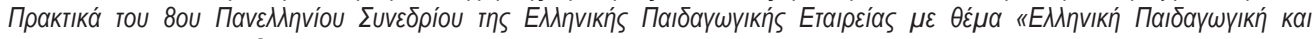

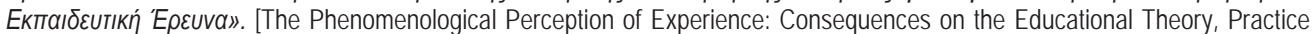
and Research. Proceedings of the $8^{\text {th }}$ Panellenic Congress of the Greek Educational Society on the subject "Greek Pedagogical and Educational Research"].

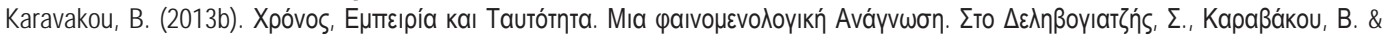

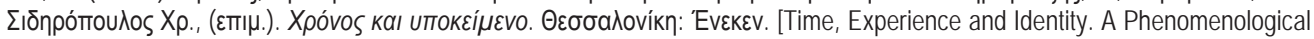
Reading. In Delivogiagis, S., Karavakou, B. \& Sidiropoulos, Chr. (Eds). Time and Subject. Thessaloniki: Eneken].

Kavouras, P. (1994). Where the community 'reveals itself': Reflexivity and moral judgment in Karpathos, Greece. In K. Hastrup - P. Hervik (Eds.), Social experience and anthropological knowledge (pp. 139-165). London: Routledge.

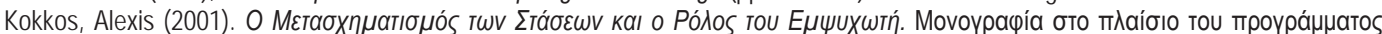

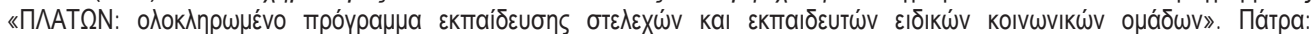

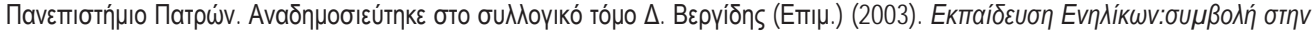

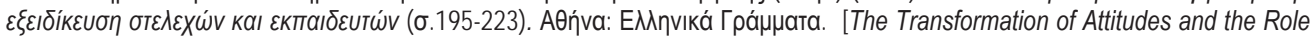
of the Animator. Monograph in the frame of the program "PLATO: an integrated program for the training of executives and trainers of special social groups". Patra: University of Patra. It was republished in the collective volume D. Vergidis (ed.) (2003), Adult Learning: Contribution to the Specialization of Executives and Trainers (pp. 195-223). Athens: Ellinika Grammata].

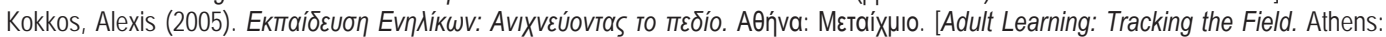
Metechmio].

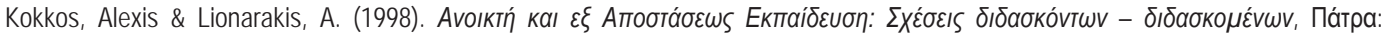

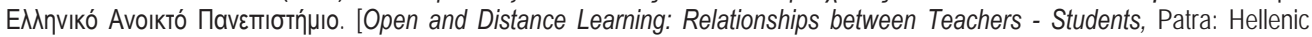
Open University].

Kokkos, A. \& Alhadeff-Jones, M. (2011). Transformative Learning in Time of Crisis: Individual and Collective Challenges. In Proceedings of the 9th International Transformative Learning Conference. Athens: Hellenic Adult Education Association.

Kokkos, A. (2011). Transformative Learning Through Aesthetic Experience: Towards a Comprehensive Method. Journal of Transformative Education July 2010, 8, 155-177.

Kokkos, A. (2012a). The method of 'Critical and Creative Learning through Aesthetic Experience' In L.Ezechil (Ed.), Innovative Methods 
in Adult Education (pp.141-148). Romania: University of Pitesti.

Kokkos, A. (2012b). Transformative Learning in Europe: An overview of the Theoretical Perspectives. In E. Taylor \& P. Cranton (Eds.), The Handbook of Transformative Learning. Theory, Research and Practice (pp. 289-303). San Francisco: Jossey- Bass.

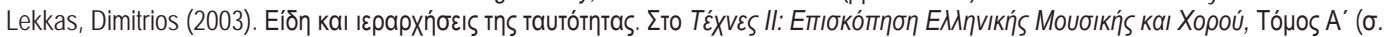
124-129). Пáтpa: ЕАП. [Kinds and Hierarchizations of Identity. In Arts II: An Overview of Greek Music and Dance, Volume A (pp. 124-129). Patra: Hellenic Open University].

Marvin, Harris (1968). Emics, Etics and the New Ethnography. In Morton H. Fried (ed.), Readings in Anthropology (pp. 102-135). Néa Yópкn: Thomas Y. Crowell Company.

Mezirow, J. (1991). Transformative dimension of Adult Learning. San Francisco: Jossey - Bass.

Nettl, Bruno (2002). Encounters in Ethnomusicology. A memoir. Michigan: Harmonie Park Press.

Papakostas, Chr., Goulimaris, D., Douma M. Dynamic musicscapes in Northern Greece: A roma case study. Folklore. Electronic Journal of Folklore, In Press.

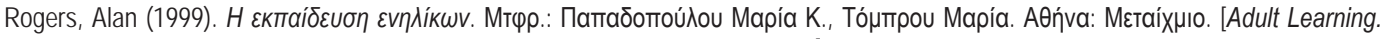
Translation: Papadopoulou Maria K., Tombrou Maria. Athens: Metechmio].

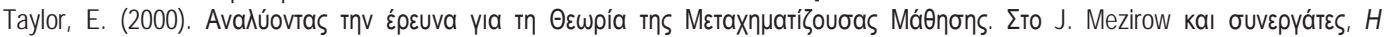

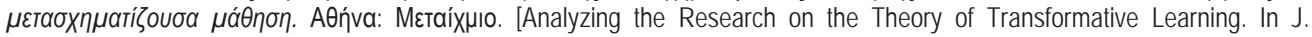
Mezirow, Transformative Learning. Athens: Metechmio].

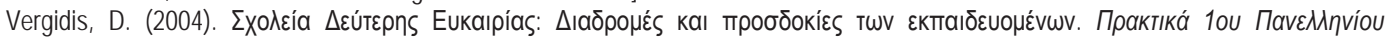

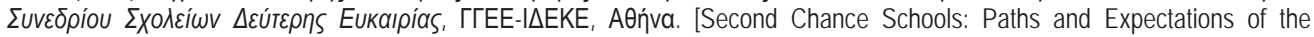
trainees. [Proceedings of the 1st Panhellenic Congress of Schools of Second Chance, Athens].

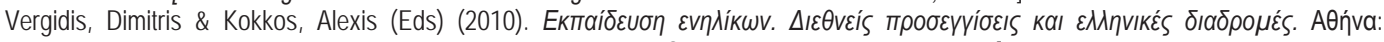
Meтaíxuı. [Adult Learning. International Approaches and Greek Paths. Athens: Metechmio].

Voutsina, M. \& Goulimaris, D. (2016). Motivation and job satisfaction of people working in recreational dance activities. Sport Science, $9,1$. 